\title{
How to Design a Successful Digital Product? An Analytic Hierarchy Process (AHP) Analysis of Expert Opinions from the Berlin Start-up Scene
}

\author{
Muhammad Yusuf Azka \\ The MietMiet Company \\ azka@mietmiet.com
}

\author{
Stanislav Chankov \\ Jacobs University Bremen, Germany \\ s.chankov@jacobs-university.de
}

\begin{abstract}
Designing the best digital product is vital for the competitiveness of any organization. Thus, this paper aims to determine the critical success design factors and to create guidelines for start-up founders, product managers, designers and entrepreneurs on how to design a successful digital product. To this end, six key design factors and 24 respective sub-factors were identified based on literature and expert opinions. Further, 21 experts were surveyed regarding their priorities on these factors, using the analytic hierarchy process (AHP). The results suggest that high-level planning design is the most important success factor, while having clear product vision, discovery, strategy and goals, building a great user experience, and creating an aesthetic user interface are the top three priority sub-factors for successful digital products.
\end{abstract}

\section{Introduction}

The importance of design in product development has become a top-management issue, with corporates and startups having trouble to distinguish their digital or physical products from the crowd [1]. While digital economy has replaced some of traditional processes, $90 \%$ of digital startups fail, and two of the biggest reasons are "The product is not perfect for the market" and "the founders ignore the importance of product and design processes" [2]. Over the past 50 years, there has been a concrete correlation in design importance, in which the S\&P index increase when S\&P 500 firms, such as Nike, Netflix, Amazon, Disney, P\&G, invested their resources most into product, design and processes: such that, McKinsey reported these firms reached a $\$ 39,427$ index (known as design-value index) and outperformed the rest of the S\&P index by $219 \%$ in 2015 [1]. This shows the importance of design. As Airbnb's co-founder Gebbia put it "for every tech startup and business, design lies at its core of success"[3].

Various design factors for the success of digital products have been researched [4]-[9]. There are mostly six factors of design in a tech organization, where modern digital products are being developed: (1) highlevel planning design [4], (2) tech/ engineering stacks design [6], (3) aftersales design [5], (4) process design [7], (5) graphic and visual design [8], and lastly (6) addons or aesthetic design [9]. Each of which consists of several sub-factors. Hence, understanding which design factors and sub-factors have an impact towards the success of a digital product would be helpful to adopt efficient design iteration phase from start to end.

Even though previous research [10] has studied the impact of different entrepreneurial, economic, and marketing factors on the success of a digital startup, there is a research gap when it comes to the impact of design factors and sub-factors for a successful digital product. Accordingly, the purpose of this paper is to determine the critical success design factors and to create guidelines for founders, product managers, designers, and entrepreneurs (FPmDEs) on how to design a successful digital product. First, a detailed literature review, complemented by 10 expert interviews, was carried out to identify and validate relevant design factors and sub-factors of a successful digital product. Second, to analyze the importance of design factors and sub-factors, an Analytic Hierarchy Process (AHP) analysis was conducted on data collected by survey of 21 designers, founders and technology enthusiasts from the Berlin start-up scene. Third, we derive recommendations for FPmDEs on which design factors and sub-factors to prioritize.

Accelerators, venture capital funds, private equity firms, consultancy agencies, and government organizations can use this paper as a playbook for any founding team they support or finance to achieve a successful digital product and product-market fit stage.

\section{Framework development}

A literature review regarding design factors and subfactors that influence the success of digital products was performed. Six main design factors and multiple respective sub-factors that impact the success of a digital product were identified. Further, these factors and sub-factors were verified by 10 experts through 
Figure 1. Digital product design framework

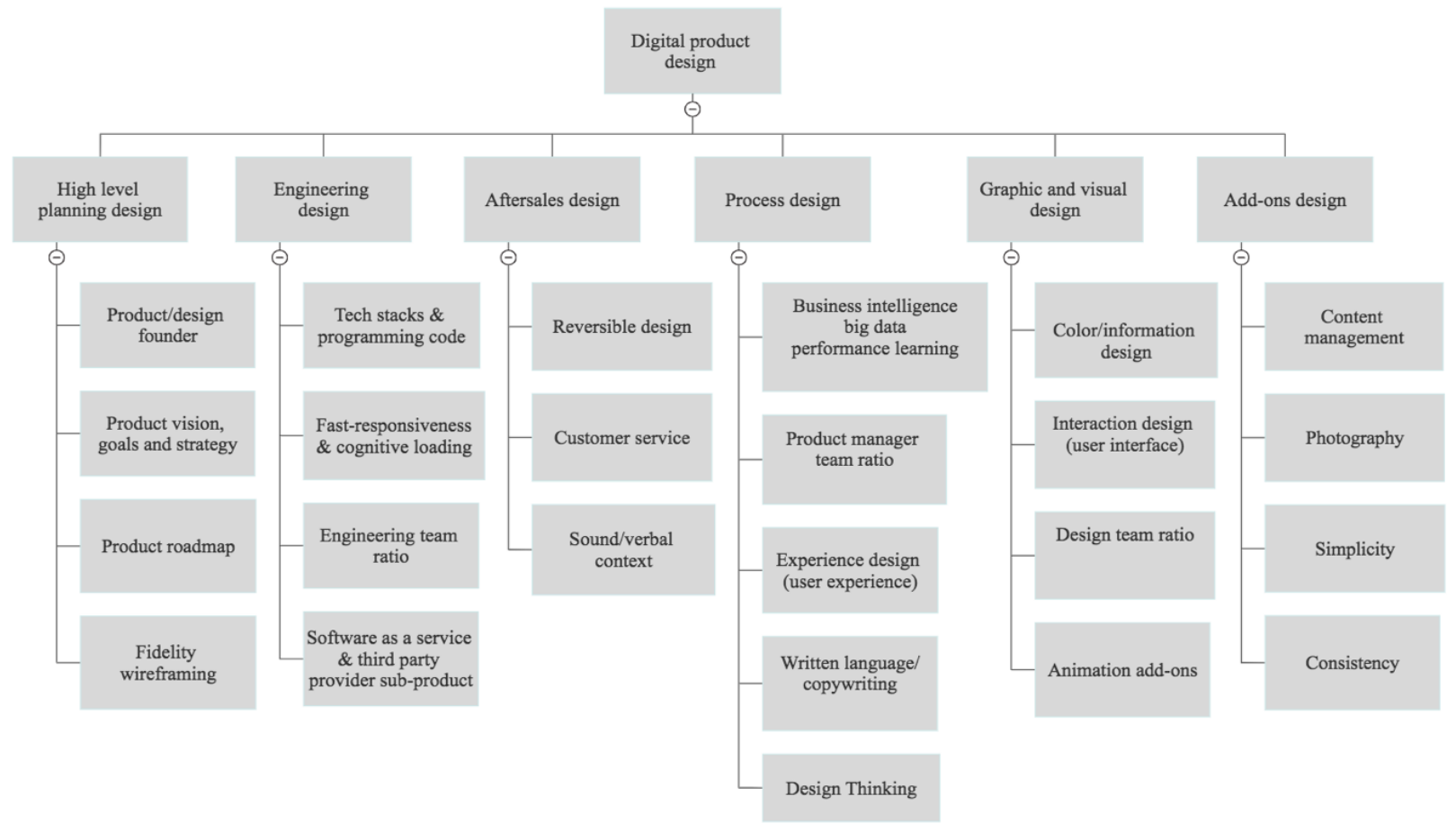

semi-structured interviews. Thus, a digital product design framework was developed (see Figure 1).

The six identified design factors are: (1) high-level planning design, (2) tech/engineering stacks design, (3) aftersales design, (4) process design, (5) graphic and visual design, and (6) add-ons or aesthetic design.

The first design factor is high-level planning design and it include sub-factors such as: product / design founder, product roadmap, and fidelity wireframing [11]-[13]. The second factor is engineering design and it includes sub-factors such as tech stacks/programming, fast-responsiveness \& cognitive loading, engineering team ratio and software as a service $(\mathrm{SaaS}) \&$ third-party provider sub-product [14]-[18]. The third factor is aftersales design factor and it includes sub-factors such as customer service, reversible design, and sound/verbal context [19]-[24]. The fourth factor, process design, includes sub-factors such as business intelligence (BI) / big data / performance learning, product manager team ratio, experience design/user experience, written language/copywriting, and design thinking [7], [25] [30]. The fifth factor, graphic and visual design, includes color / information design, user interface / interaction design, design team ratio, and animation add-on [31]-[34]. The last factor, add-ons design, includes sub-factors of content management and photography [35], [36].

To ensure that the findings of the literature review are valid, we conducted semi-structured interviews with 10 experts, who have a design or product management background. A total of 52 experts from Factory Berlin (one of the largest co-working space communities of innovators in Berlin) were contacted, out of which 10 agreed to participate. Only design experts who are either a founder, entrepreneur, designer, product manager, and C-level executives were interviewed. The selected experts had between 3 and 30 years of experience, with an average of $11+$ years of experience and represented diverse industries (travel, fashion, blockchain, artificial intelligence, social media, hardware) ensuring a broad expert perspective. Face-to-face interview sessions were then conducted, averaging 15 minutes each. The recorded interviews are available on request.

The data obtained during the interviews confirmed all design factors and sub-factors identified in the literature. Further, through two expert interviews, two additional sub-factors part of the adds-on design factor (simplicity and consistency) were identified, while 4 expert interviews indicated one additional sub-factor part of high-level planning design (product vision, goals and strategy).

\section{Design factors \& sub-factors}

In this section, all of the design factors and subfactors part of the digital product design framework are defined. Table 1 presents the definitions for the six main design factors and Table 2 lists the definitions of all subfactors. 


\section{Table 1. Definitions of the six main design factors}

\begin{tabular}{ll}
\hline Design factors & Definition \\
\hline $\begin{array}{l}\text { High-level planning } \\
\text { design }\end{array}$ & $\begin{array}{l}\text { How an organization executes the product, design tasks on a managerial level and aligns all stakeholders } \\
\text { together [4], [37]. }\end{array}$ \\
Engineering design & $\begin{array}{l}\text { How an organization manages its programming languages and codes, develops its software, and operates } \\
\text { its server, database and architecture [38], [39]. }\end{array}$ \\
Aftersales design & $\begin{array}{l}\text { How an organization identifies its after sales process, supplementary services, and customer } \\
\text { benchmarking to enhance customer satisfaction [40], [41]. }\end{array}$ \\
Process design & $\begin{array}{l}\text { How an organization uses data analytics, business intelligence, user experience, and scrum methodology } \\
\text { to leverage product development [7]. }\end{array}$ \\
$\begin{array}{l}\text { How an organization incorporates creative visual arts discipline (art direction, page layout, fonts, color, } \\
\text { tesign and visual }\end{array}$ & $\begin{array}{l}\text { typography, etc.) in its product [42]. } \\
\text { How an organization uses content management, photography, simplicity, consistency, and branding } \\
\text { together to refine the product [35], [36], [43], [44]. }\end{array}$ \\
\hline
\end{tabular}

Table 2. Definitions of all sub-factors

\begin{tabular}{ll}
\hline High-level planning & Definition \\
\hline $\begin{array}{l}\text { Product / Design } \\
\text { founder }\end{array}$ & $\begin{array}{l}\text { One founder or executive, who has a background in designing or building products, needs to be in the } \\
\text { management [11]. }\end{array}$ \\
$\begin{array}{l}\text { Product Vision, } \\
\text { Goals and Strategy }\end{array}$ & $\begin{array}{l}\text { A strong alignment of an organization's product vision, goals and strategy is required to produce a product } \\
\text { roadmap that generates realistic milestones and execution for the company [12]. }\end{array}$ \\
$\begin{array}{l}\text { Product roadmap } \\
\text { A high-level visual summary that outlines the vision and direction of a digital product over the lifetime } \\
\text { Fidelity wireframing }\end{array}$ & $\begin{array}{l}\text { value [12]. } \\
\text { The skeleton of any interface and design to provide a structure of design as initial prototype to achieve } \\
\text { product-market fit [13]. }\end{array}$
\end{tabular}

\begin{tabular}{l}
\hline Engineering \\
\hline Tech stacks / \\
programming \\
Fast-responsiveness \\
\& cognitive loading \\
Engineering team \\
ratio
\end{tabular}

SaaS \& Third Party The engineering operations in which an organization cannot develop its sub-product by themselves, so a Provider sub-product third party partner is necessary [17].

\begin{tabular}{|c|c|}
\hline Aftersales & Definition \\
\hline Reversible design & $\begin{array}{l}\text { An access for a user to previous state or situation, known as "reversible", to provide seamless user } \\
\text { experience and minimize confusion [19]. }\end{array}$ \\
\hline Customer service & $\begin{array}{l}\text { A "code of practice" for organization to value further their customers through customer calls, emails [20]- } \\
\text { [22]. }\end{array}$ \\
\hline $\begin{array}{l}\text { Sound / verbal } \\
\text { context }\end{array}$ & $\begin{array}{l}\text { The availability of the sound attached to a product, experienced by the user; working sounds (sounds } \\
\text { generated by products while working), interaction sounds (sounds generated by the interaction of the user } \\
\text { with the product), and communication sounds (sounds generated to give some info to the user) [23]. Sound } \\
\text { is part of the user experience, but can be independently classified as its own sub-factor for a better } \\
\text { awareness for the target group FPmDE, due to its emphasis in any product development [24]. }\end{array}$ \\
\hline Process & Definition \\
\hline $\begin{array}{l}\text { BI / Big Data / Deep } \\
\text { \& Perf. Learning }\end{array}$ & $\begin{array}{l}\text { A purely data-centric process would give better leverage in the development of a digital product } \\
\text { development [7]. }\end{array}$ \\
\hline $\begin{array}{l}\text { Product manager } \\
\text { team ratio }\end{array}$ & $\begin{array}{l}\text { The number of product managers in the team should be balanced according to the product vision and } \\
\text { goals. A good size of a product manager team is } 7 \pm 2 \text { developers for every product manager [25], [26]. }\end{array}$ \\
\hline $\begin{array}{l}\text { Experience Design } \\
\text { (User Experience) }\end{array}$ & A person's perceptions and responses, which resulted from the use of a product, service, or system [27]. \\
\hline $\begin{array}{l}\text { Written language / } \\
\text { copywriting }\end{array}$ & The art and science of explaining a product by written or spoken words [28], [29]. \\
\hline Design Thinking & $\begin{array}{l}\text { A specific method, rules and procedures to solve complex problems and, therefore, to come up with } \\
\text { innovative solutions, supported by a user-centered approach with multi-disciplinary teams [30]. }\end{array}$ \\
\hline Graphic and visual & nition \\
\hline $\begin{array}{l}\text { Color / Information } \\
\text { Design }\end{array}$ & [31]. \\
\hline
\end{tabular}


Interaction Design

(User Interface)

Design team ratio

Animation add-on
A standard by which the functionality or visual product can be used; any visual perception of the product is part of the user interface, which can be used, touched or perceived by the user [32].

The number of designers in the team, who can execute the design tasks through apps such as Adobe XD, Sketch, Photoshop and Illustrator, should be balanced according to the product vision and goals [33].

A method in which individual features, interfaces, images, layouts are combined in order to appear into smooth singular or plural motion, thus making user interface more appealing, usable and lively [34].

\begin{tabular}{ll}
\hline Add-ons & Definition \\
\hline Content Management & $\begin{array}{l}\text { The tasks of content creation, aggregation, categorization, scheduling, staging, publication and } \\
\text { syndication" belong to content management, which acts as an integral added factor in a digital product } \\
\text { and incorporates attributes such as category, price, location, and promotion eligibility [35]. }\end{array}$ \\
A language that uses the means of cameras and other captural devices to produce a visual image or context \\
Photography & [36], [45]. \\
The fewer features, options and functions available on the user interface and visual context of digital \\
product itself, the less information a user needs to process mentally [43]. \\
Consistency & A consistent design allows a user to focus on understanding the product and executing the task [44].
\end{tabular}

\section{Analytic hierarchy process (AHP)}

\subsection{Methodology}

Decisions in start-ups and top management nowadays often involve multiple criteria or objectives. The analytic hierarchy process (AHP), founded by [46], is one widely used decision-making procedure for establishing priorities in multi-criteria decision problems [47], [48] due to its simplicity, ease of use, and great flexibility. The AHP consists of an eigenvalue approach to pairwise comparisons, which provides a numeric scale for the measurement of quantitative as well as qualitative performance. The AHP method consists of four basic steps [49]: (1) structuring the problem into a hierarchy of sub-problems, (2) pairwise comparisons of the attributes, (3) consistency checks, and (4) calculation of priority weights of factors and sub-factors at each level.

Accordingly, in this paper, the AHP method was used for prioritizing effective design factors when building a digital product. Pairwise comparisons were used on a standardized nine-point scale (see Table 3). The aim is to determine the relative priorities (importance) of the elements within each level [50]. These comparisons are made with respect to the given criterion of the control hierarchy and importance weights of each factor are calculated [51]. In pairwise comparison, decision makers who have the expertise knowledge on related subject compare the elements in pairs. The degree of preference, factor, and their definitions are given with the detailed explanations from 1 to 9 in Table 3 with the reciprocals for inverse comparisons.

The calculated values of pairwise comparisons are allocated in a pairwise comparison matrix, in which, each element $\left(a_{\mathrm{ij}}\right)$ represents the degree preference of the $i^{\text {th }}$ criterion over the $j^{\text {th }}$ criterion (see Equation (1)). The priority vector is derived from the eigenvector of the matrix.

$$
\text { (1) } E=\left[\begin{array}{ccc}
a_{11} & \cdots & a_{1 n} \\
\vdots & \ddots & \vdots \\
a_{n 1} & \cdots & a_{n n}
\end{array}\right]
$$

Each criterion is quantified by finding the value of the maximized eigenvalue, consistency index (CI), and consistency ratio (CR) [52]. The CR is used in order to maintain consistency in the decision-making of the responder. If $\mathrm{CR}$ is less or equal to 0.10 , the comparisons are acceptable. Otherwise, the pairwise

\section{Table 3. Saaty's comparison scale [51]}

\begin{tabular}{lll}
\hline Preference factor & Degree of preference & Explanation \\
\hline 1 & Equally & Two factors contribute equally to the objective. \\
3 & Moderately & Experience and judgment moderately favor one factor over another. \\
5 & Strongly & Experience and judgment strongly favor one factor over another. \\
7 & Very Strongly & $\begin{array}{l}\text { One factor is very strongly favored over another and its dominance } \\
\text { is demonstrated in practice. }\end{array}$ \\
9 & Extremely & The evidence favoring one factor over another appears irrefutable. \\
$1 / 3,1 / 5,1 / 7,1 / 9$ & Reciprocal & Reciprocals for inverse comparisons. \\
\hline
\end{tabular}


Table 4. The random consistency index [51]

\begin{tabular}{cccc}
\hline $\mathrm{n}$ & $\mathrm{RC}$ & $\mathrm{n}$ & $\mathrm{RC}$ \\
\hline 1 & 0.00 & 6 & 1.24 \\
2 & 0.00 & 7 & 1.32 \\
3 & 0.58 & 8 & 1.41 \\
4 & 0.90 & 9 & 1.46 \\
5 & 1.12 & 10 & 1.49 \\
\hline
\end{tabular}

comparison results are not acceptable and should be revised, which, in consequence, means that the procedure has to be repeated until each comparison satisfies the consistency criterion [53]. This CR index is computed as follows [54]:

$$
\text { (2) } \mathrm{CR}=\frac{C I}{R C}
$$

The consistency index (CI) value can be computed using Equation (3), while the random consistency (RC) index value can be obtained from Table 4.

$$
\text { (3) } \mathrm{CI}=\frac{\lambda_{\max }-n}{n-1}
$$

Here, $\lambda_{\max }$ is the maximum eigenvalue of the matrix and $n$ is the matrix size $(n \times n)$ [52].

In the last step of the AHP method, the quantitative execution and mathematical process begins to normalize and determine the weights for each evaluation matrix.
This process requires dividing the elements of each column by the sum of the elements of the same column [55]. Then the weights are calculated as the row average of the normalized matrix.

\subsection{Expert survey}

Following the digital product design framework (Figure 1) and the AHP comparison scale (Table 3), a survey was developed asking experts to rate the importance between the different design factors and sub-factors. The survey was filled in by 21 design experts who are executives in tech companies, founders, entrepreneurs, designers, or product managers, who can be grouped into product founder, design founder, founder, designer, and executive designer (see Table 5).

\subsection{Results}

The experts' evaluations of the design factors and sub-factors were consistent in most cases (see Table 6). The few exceptions (CR larger than 10\%) were excluded from the analysis as they could indicate wrong survey entries and the experts were unfortunately not available to re-examine their inconsistent answers.

The AHP results can be considered in three different ways: (1) design factors priorities, (2) global sub-factors priorities and (3) local sub-factor priorities.

Table 5. List of the 21 AHP survey design experts

\begin{tabular}{rrllll}
\hline No. & Experience & Current Position & Company Size ${ }^{\text {NB }}$ & \multicolumn{1}{c}{ Company } & Group \\
\hline 1 & 3 years & CEO & Startup & The MietMiet Company & Product Founder \\
2 & 11 years & Co-Founder & Micro & Topia & Design Founder \\
3 & 20 years & CEO & Startup & Sustainable Fashion Matterz & Founder \\
4 & 8 years & UI/UX Designer & Massive & Volkswagen Group & Designer \\
5 & 5 years & CSO & Startup & The MietMiet Company & Founder \\
6 & 11 years & Co-Founder & Startup & MyStudyGenius & Product Founder \\
7 & 7 years & CPO & Small & Donut Technologies & Product Founder \\
8 & 11 years & CEO & Startup & Maji Studio & Designer \\
9 & 14 years & Freelance Designer & Startup & Assaf Reeb Consulting & Designer \\
10 & 14 years & VP User Experience & Large & UberMedia & Executive Designer \\
11 & 8 years & CTO & Startup & The MietMiet Company & Founder \\
12 & 14 years & CEO & Startup & Spicii Chocolate & Designer \\
13 & 15 years & VP Design & Massive & Emirates NBD & Executive Designer \\
14 & 2 years & Freelance Designer & Startup & Radwa Osama Design & Designer \\
15 & 5 years & Freelance Designer & Startup & Alina Holtmann Design & Designer \\
16 & 17 years & CDO & Massive & Tourlane & Executive Designer \\
17 & 9 years & UI/UX Designer & Massive & SumUp & Designer \\
18 & 25 years & CEO & Micro & Timeslot & Founder \\
19 & 15 years & CTO & Startup & Faer.app & Product Founder \\
20 & 2 years & Market Lead & Massive & Bumble & Executive Designer \\
21 & 10 years & CEO & Micro & Twindly & Founder \\
\hline
\end{tabular}

NB Startup <5, Micro <10, Small <20, Medium <50, Large < 100, Massive > 100 
Table 6. Consistency ratios of every hierarchy

\begin{tabular}{rrrrrrrr}
\hline Expert & Big Factors & $\begin{array}{c}\text { High-level } \\
\text { Planning }\end{array}$ & Engineering & Aftersales & Process & $\begin{array}{c}\text { Graphic \& } \\
\text { Visual }\end{array}$ & Add-ons \\
\hline 1 & $9 \%$ & $3 \%$ & $1 \%$ & $3 \%$ & $9 \%$ & $\mathbf{1 2 \%}$ & $3 \%$ \\
2 & $7 \%$ & $7 \%$ & $0 \%$ & $0 \%$ & $5 \%$ & $9 \%$ & $6 \%$ \\
3 & $7 \%$ & $10 \%$ & $2 \%$ & $0 \%$ & $10 \%$ & $10 \%$ & $8 \%$ \\
4 & $10 \%$ & $9 \%$ & $7 \%$ & $0 \%$ & $6 \%$ & $10 \%$ & $2 \%$ \\
5 & $8 \%$ & $4 \%$ & $3 \%$ & $1 \%$ & $10 \%$ & $2 \%$ & $6 \%$ \\
6 & $\mathbf{1 2 \%}$ & $6 \%$ & $9 \%$ & $0 \%$ & $2 \%$ & $4 \%$ & $3 \%$ \\
7 & $10 \%$ & $4 \%$ & $5 \%$ & $3 \%$ & $9 \%$ & $8 \%$ & $4 \%$ \\
8 & $4 \%$ & $3 \%$ & $6 \%$ & $3 \%$ & $10 \%$ & $10 \%$ & $1 \%$ \\
9 & $0 \%$ & $10 \%$ & $10 \%$ & $6 \%$ & $7 \%$ & $6 \%$ & $5 \%$ \\
10 & $\mathbf{1 2 \%}$ & $7 \%$ & $5 \%$ & $0 \%$ & $10 \%$ & $4 \%$ & $10 \%$ \\
11 & $\mathbf{1 3 \%}$ & $\mathbf{1 5 \%}$ & $5 \%$ & $1 \%$ & $10 \%$ & $7 \%$ & $\mathbf{2 2 \%}$ \\
12 & $7 \%$ & $7 \%$ & $\mathbf{2 7 \%}$ & $6 \%$ & $9 \%$ & $\mathbf{2 5 \%}$ & $\mathbf{1 3 \%}$ \\
13 & $10 \%$ & $3 \%$ & $7 \%$ & $0 \%$ & $2 \%$ & $2 \%$ & $3 \%$ \\
14 & $7 \%$ & $8 \%$ & $4 \%$ & $\mathbf{1 8 \%}$ & $9 \%$ & $6 \%$ & $9 \%$ \\
15 & $8 \%$ & $9 \%$ & $8 \%$ & $1 \%$ & $\mathbf{3 3 \%}$ & $10 \%$ & $9 \%$ \\
16 & $8 \%$ & $7 \%$ & $4 \%$ & $10 \%$ & $5 \%$ & $10 \%$ & $8 \%$ \\
17 & $7 \%$ & $5 \%$ & $5 \%$ & $0 \%$ & $5 \%$ & $\mathbf{1 2 \%}$ & $1 \%$ \\
18 & $4 \%$ & $5 \%$ & $3 \%$ & $0 \%$ & $6 \%$ & $4 \%$ & $1 \%$ \\
19 & $4 \%$ & $3 \%$ & $4 \%$ & $0 \%$ & $2 \%$ & $5 \%$ & $0 \%$ \\
20 & $3 \%$ & $7 \%$ & $0 \%$ & $0 \%$ & $6 \%$ & $0 \%$ & $5 \%$ \\
21 & $4 \%$ & $5 \%$ & $2 \%$ & $0 \%$ & $10 \%$ & $1 \%$ & $3 \%$ \\
\hline Mean & $7.3 \%$ & $6.5 \%$ & $5.6 \%$ & $2.5 \%$ & $8.3 \%$ & $7.4 \%$ & $5.7 \%$ \\
\hline
\end{tabular}

First, aggregating 18 experts' opinions on the six main design factors (three experts have CR of more than $10 \%$ ) gives the priority weights for digital product design factors on the first level (see Table 7). The results show that for the success of a digital product, it is important to prioritize the tasks of high-level planning design, complemented by process design as part of the initial validation of the market research, data analytics, and the initial tasks to build the product. The graphic and visual design ranks third, as it is also critical to focus on having attractive interface and visuals on the digital product, which could be complemented by the add-ons design. Lastly, the engineering design comes to the second last priority and aftersales design comes last.

Second, Table 8 shows the AHP results on the second level criteria for all sub-factors of each of the six main design factors. On a global scale, having clear product vision, discovery, strategy and goals, building a great user experience, and creating an aesthetic user interface are the top three priority sub-factors.

Third, on a local scale, product vision, goals and strategy was the most important sub-factor for highlevel planning design. Engineering team ratio and fast responsiveness and cognitive loading scored both very high for engineering design while reversible design scored the highest for aftersales design. At the secondlevel criteria for process design, experience design or user experience got the highest weight, while for graphic and visual design, interaction design or user interface was the highest. Finally, for add-ons design, consistency and content management were almost equally important, scoring higher than the other two sub-factors.

\section{Discussion: guidelines for FPmDEs}

In regards to the recommendation guidelines for any founders, product managers, designers and entrepreneurs (FPmDEs) who want to build a successful digital product, it is viable to look at a local scale level: "design factor by design factor" basis.

\subsection{High-level planning design}

The results of this paper show that FPmDEs should prioritize on distributing resources to enhance the high-

Table 7. AHP Results on the six design factors

\begin{tabular}{lcc}
\hline Evaluation Design Factors & Weight & Priority \\
\hline High-level planning design & 0.268 & 1 \\
Engineering design & 0.077 & 5 \\
Process design & 0.248 & 2 \\
Graphic and Visual design & 0.234 & 3 \\
Aftersales design & 0.070 & 6 \\
Add-ons design & 0.102 & 4 \\
\hline
\end{tabular}


Table 8. AHP Results of all design factors and sub-factors

\begin{tabular}{|c|c|c|c|c|c|c|}
\hline \multirow{2}{*}{$\begin{array}{c}\text { Evaluation } \\
\text { Factors }\end{array}$} & \multirow{2}{*}{$\begin{array}{l}\text { Weight } \\
\text { Local }\end{array}$} & \multirow{2}{*}{$\begin{array}{l}\text { Evaluation } \\
\text { Sub-Factors }\end{array}$} & \multicolumn{4}{|c|}{ Weight of Evaluation Sub-Factors } \\
\hline & & & Local & Priority & Global & Priority \\
\hline \multirow{4}{*}{$\begin{array}{l}\text { High-level } \\
\text { planning design }\end{array}$} & \multirow{4}{*}{0.268} & Product/Design founder & 0.1596 & 2 & 0.0428 & 5 \\
\hline & & Product Vision, Goals and $\mathrm{S}$ & 0.5300 & 1 & 0.1423 & 1 \\
\hline & & Product roadmap (LR) & 0.1595 & 3 & 0.0428 & 6 \\
\hline & & Fidelity wireframing & 0.1510 & 4 & 0.0405 & 8 \\
\hline \multirow{4}{*}{$\begin{array}{l}\text { Engineering } \\
\text { Design }\end{array}$} & \multirow{4}{*}{0.077} & Tech stacks/programming & 0.2020 & 3 & 0.0156 & 22 \\
\hline & & Fast-response \& cognitive loading & 0.3200 & 2 & 0.0247 & 16 \\
\hline & & Engineering team ratio & 0.3295 & 1 & 0.0254 & 15 \\
\hline & & Third party providers/in & 0.1486 & 4 & 0.0115 & 24 \\
\hline \multirow{3}{*}{$\begin{array}{l}\text { Aftersales } \\
\text { Design }\end{array}$} & \multirow{3}{*}{0.070} & le Design & 0.5406 & 1 & 0.0379 & 9 \\
\hline & & Customer Service & 0.2851 & 2 & 0.0200 & 20 \\
\hline & & Sound/Verbal Context & 0.1742 & 3 & 0.0122 & 23 \\
\hline \multirow{5}{*}{ Process Design } & \multirow{5}{*}{0.248} & BI/ Big Data/ Performance Learning & 0.1702 & 2 & 0.0422 & 7 \\
\hline & & Product Manager team ratio & 0.1265 & 4 & 0.0314 & 11 \\
\hline & & Experience Design (User Experience) & 0.4598 & 1 & 0.1141 & 3 \\
\hline & & Written/Copywriting Language & 0.0952 & 5 & 0.0236 & 17 \\
\hline & & Design Thinking/Scrum Met & 0.1482 & 3 & 0.0368 & 10 \\
\hline \multirow{4}{*}{$\begin{array}{l}\text { Graphic and } \\
\text { Visual Design }\end{array}$} & \multirow{4}{*}{0.234} & Color/Information Design & 0.1295 & 3 & 0.0303 & 14 \\
\hline & & Design (User Int & 0.5769 & 1 & 0.1351 & 2 \\
\hline & & Design team ratio & 0.2067 & 2 & 0.0484 & 4 \\
\hline & & Animation add-on & 0.0869 & 4 & 0.0203 & 19 \\
\hline \multirow{4}{*}{ Add-ons Design } & \multirow{4}{*}{0.102} & Content Management & 0.2987 & 2 & 0.0304 & 13 \\
\hline & & Photography & 0.1923 & 4 & 0.0196 & 21 \\
\hline & & Simplicity & 0.2048 & 3 & 0.0209 & 18 \\
\hline & & Consistency & 0.3041 & 1 & 0.0310 & 12 \\
\hline Total & 1.000 & & 6.0000 & & 1.0000 & \\
\hline
\end{tabular}

level planning design (0.268) first, before jumping in to other parts of the design processes of the organization, especially during the start-up or early stage. When exploring about the high-level planning design further, having a clear product vision, goals and strategy $(0.5300)$ is almost four time more important to other sub-factors such as having a product/design founder (0.1596), achieving a transparent and realistic product roadmap (0.1595), or building the first fidelity wireframing $(0.1510)$. Even though there is a clear hierarchy of ranks amongst the four sub-factors, having a product-design founder, outlining a clear product roadmap, and creating an initial fidelity wireframing are almost equally important. This means that a lot of investment, time, and energy will be a waste, if an organization takes the three less important sub-factors into account firstly, before understanding and implementing the work needed to achieve a clear product vision, goals and strategy.

\subsection{Process design}

Once all of the work, tasks and requirements within the high-level planning design are performed, FPmDEs have to prioritize process design $(0.248)$ factors to further enhance the necessary requirements post highlevel planning. The results of this paper show that FPmDEs should prioritize creating a world-class and seamless user experience (0.4598), as it is three times more important than performing business intelligence and data analytics (0.1702) work and iterating the product development using design thinking / scrum methodology (0.1482), and four times more important than hiring balanced product managers team ratio $(0.1265)$ and putting efforts in enhancing the content through excellent copywriting and written language (0.0952). Even though the user experience sub-factor ranks the first, other sub-factors in process design should not be neglected.

\subsection{Graphic and visual design}

The next critical design factor for a successful digital product is graphic and visual design (0.234). This implies that after having taken consideration of highlevel planning design and process design, it is very critical to understand the impact of graphic and visual design towards a successful digital product, as the local ranking weight between the top three design factors have a difference only $3-4 \%$. Within the graphic and 
visual design, it can be inferred that interaction design and user interface (0.5769) have significant impact, showing that FPmDEs should implement an aesthetic, yet simple and consistent, user interface for the users. Additionally, design team ratio $(0.2067)$ ranks $2^{\text {nd }}$ in the hierarchy, followed by color / information design (0.295), and animation add-on (0.0869). Thus, we suggest that the ranking weights should be considered when allocating time, money, and human resources for each design sub-factor: for example, FPmDEs should invest several times more in terms of time, money or resources to design the best user interface than to decide on which animations to use in the product itself.

\subsection{Add-ons design}

Following the graphic and visual design, add-ons design (0.102) comes next with a more than two times lower weight. This implies that FPmDEs are advised to invest roughly $50 \%$ less time, money or resources for add-ons design than those dedicated to the first top three factors. Within the add-ons design, it can be inferred that consistency (0.3041) and content management (0.2987) have significant impact, carrying $60 \%$ of the weights, while simplicity (0.2048) and photography (0.1923) carry $40 \%$ of the weights. This implies that even though the four sub-factors have hierarchy rankings, the difference is small, so FPmDEs have some flexibility which sub-factor to prioritize. However, it is advisable for the FPmDEs to consider the current hierarchy system, as a guideline when building a digital product.

\subsection{Engineering design}

The engineering aspect of the design (0.077) ranks $5^{\text {th }}$ on the hierarchy, which implies that the engineering and architecture behind it are not so important during the start-up and early stage phase. Several experts also validate that when a founder wants to start a business idea, their main focus is to validate their idea through a fast minimum viable product, and later on build upon their current product and improve their architecture. One of the expert in this paper stated that

"There are two approaches: tech-centric and customercentric. The one that starts to build with technology or tech-centric, then get the customers around it. So, in this case, $99 \%$ of teams using this methodology will fail. The other one if starting first with getting customers and solving their problems with the worse technology and iterate afterwards: in this case, it is most likely to be very successful. Always be customer-centric to have a successful product, rather than refining your engineering, before finding a product-market fit".
However, within the engineering design hierarchy, it is advisable for FPmDEs to focus on the skilful engineering team $(0.3295)$ they hire, followed by fastresponsiveness \& cognitive loading (0.3200), which shows that "having a digital product that is fast and does not confuse the user / take high loading times" is almost equally important as "fulfilling to have enough engineers to build and sustain an organization's digital product". Furthermore, the choice of tech stacks or programming languages $(0.2020)$ of the digital product comes to the third priority, followed by the third party providers or integrations $(0.1486)$ being used by the digital product itself.

\subsection{Aftersales design}

Last but not least, the aftersales design (0.070) complements the whole six design factors, in which reversible design (0.5406) carries two times more importance than customer service (0.2851) and three times more importance than sound / verbal context (0.1742). This implies that, even though aftersales design carries a much smaller weight than the other five design factors, the existence of it should not be neglected. FPmDEs should also understand the importance of aftersales design is comparably similar to engineering design, and perhaps the phase in which these aftersales design sub-factors can be implemented will come at the end phase of the digital product. Within the aftersales design, it can be concluded that FPmDEs should put much higher consideration in their reversible user experience of their digital product, compared to the customer service factor.

\section{Conclusion}

The main objective of this paper was to determine which design factors and sub-factors to prioritize, in order to have a successful digital product. The results suggest that high-level planning design is the most important success factor, while having clear product vision, discovery, strategy and goals, building a great user experience, and creating an aesthetic user interface are the top three priority sub-factors for successful digital products.

The main strength of this paper is that, according to authors' knowledge, it provides a new approach in prioritizing design factors and sub-factors, by weighing them on a multi-dimensional level, using AHP. Besides, it gives FPmDEs the chance to ease how they make their management decisions, when a lot of variables are at stake. The main limitation is that the experts' bias is not acknowledged, but having 21 experts contributing to the AHP analysis should eliminate that bias. 
Since this study does not provide clear results on the timing or phasing dimension of when the design factors and sub-factors should be implemented or not, a detailed research aligning the exact timing of when these design factors and sub-factors should be acknowledged better by FPmDEs can be investigated in further research. Furthermore, since this research discusses the importance of building digital product at the very early stage, another good development or extension of this research may include "What makes digital product successful at the growth or profitable stage of a startup?". This will allow to check if the same results of design priorities can be achieved when a start-up is at early stage or later stage.

The results of the paper provide insights for founders, product managers, designers and entrepreneurs to build a successful digital product from a design perspective during the early stages. Additionally, the results can be used by both technology corporates and start-ups to adopt their design managerial decision-making processes based on this paper, at no cost. When it comes to the feasibility of implementing the design factors and sub-factors priorities, it can be argued that individual founders, product managers, designers and entrepreneurs would not be interested to implement this on a bigger picture. However, public or private supporters and funders such as accelerators, government agencies, venture capital funds, private equity firms, and investors could adopt this paper as a playbook to guide start-up founders in creating a successful and sustainable digital product.

\section{References}

[1] J. Edson, G. Kouyoumjian, and B. Sheppard, "More Than a Feeling: Ten Design Practices to Deliver Business Value," 2017.

[2] N. Patel, " $90 \%$ Of Startups Fail: Here's What You Need To Know About The 10\%," 2015. [Online]. Available:https://www.forbes.com/sites/neilpatel/2015/ 01/16/90-of-startups-will-fail-heres-what-you-need-toknow-about-the-10/\#7fa5e3966792. [Accessed: 15-Jun2019].

[3] J. Gebbia, "How Airbnb designs for trust. TED Ideas worth spreading.," 2016. [Online]. Available: https://www.ted.com/talks/joe_gebbia_how_airbnb_des igns_for_trust?language=en. [Accessed: 15-Jun-2019].

[4] C. H. Johnson, "'High Level Design ; Distributed Network Traffic Controller', 22c(198)," 2005.

[5] E. Egonsson, K. Bayarsaikhan, and T. T. Ly, "AfterSales Services and Customer Relationship Marketing," Linnaeus University, 2013.

[6] AirStack, "The 2019 guide to Tech Stack Management," 2019.

[7] M. Brambilla, S. Ceri, P. Fraternali, and I. Manolescu, "Process modeling in Web applications," ACM Trans. Softw. Eng. Methodol., vol. 15, no. 4, pp. 360-409,
Oct. 2006

[8] J. Beaird, The principles of beautiful web design. SitePoint Pty. Limited, 2007.

[9] D. Joshi et al., "On Aesthetics and Emotions in Scene Images: A Computational Perspective," Scene Vis. Mak. Sense What We See, p. 241, 2014.

[10] B. Kim, H. Kim, and Y. Jeon, "Critical Success Factors of a Design Startup Business," Sustainability, vol. 10, no. 9, p. 2981, 2018.

[11] N. Wasserman, "The founder's dilemma," Harv. Bus. Rev., vol. 86, no. 2, pp. 102-109, 2008.

[12] J. Semick, "Product Roadmaps: Your Guide to Planning and Selling Your Strategy," 2001.

[13] P. Pal, "What Is The Difference Between Low-Fidelity and High-Fidelity Wireframes?," Think360. UI/UX Design. , 2017. [Online]. Available: https://think360studio.com/difference-low-fidelityhigh-fidelity-wireframes/. [Accessed: 15-Jun-2019].

[14] Baymard Institute, "Reasons for Abandonments During Checkout," 2018. [Online]. Available: https://baymard.com/lists/cart-abandonment-rate. [Accessed: 15-Jun-2019].

[15] S. Krug, "Cognitive load," 2018. [Online]. Available: https://www.invisionapp.com/designdefined/cognitive-load/. [Accessed: 15-Jun-2019].

[16] C. Giardino, M. Unterkalmsteiner, N. Paternoster, T. Gorschek, and P. Abrahamsson, "What do we know about software development in startups?," IEEE Softw., vol. 31, no. 5, pp. 28-32, 2014.

[17] E. G. Anderson Jr, A. Davis-Blake, S. S. Erzurumlu, N. R. Joglekar, and G. G. Parker, "The effects of outsourcing, offshoring, and distributed product development organizations on coordinating the NPD process," in Handbook of new product development management, Routledge, 2007, pp. 275-306.

[18] FTMS College, "Programming Languages," Kuala Lampur, 2019.

[19] S. O'Brien, "Engineering principles: make it reversible. Inside Intercome.," 2016. [Online]. Available: https://www.intercom.com/blog/videos/engineeringprinciples-make-reversible/. [Accessed: 15-Jun-2019].

[20] L. S. Jamier, "Customer service," 2002. [Online]. Available: goodcustomerservice.com.

[21] E. A. Ako-Nai, "Effect of Customer Service on Customer Satisfaction: A Case Study of Fidelity Bank, Adum, Kumasi," 2011.

[22] H.-W. Micklitz, "Services Standards: Defining the Core Consumer Elements and their Minimum Requirements," Study Comm. by ANEC, Eur. Voice Stand., 2007.

[23] M. Ambrogio, "Virtual acoustics for product design and prototyping process," 2012.

[24] L. Foureaux, "A Quick Guide to Designing UX Sounds | Toptal,” Designers, 2019. [Online]. Available: https://www.toptal.com/designers/ux/ux-sounds-guide. [Accessed: 03-Sep-2019].

[25] K. Norton, "A Certain Ratio - What's the ideal number of engineers for every PM?," 2017. [Online]. Available: https://www.kennorton.com/newsletter/2017-03-27- 
bringing-the-donuts.html. [Accessed: 02-Sep-2019].

[26] R. Van der Merwe, "Why Companies Need Full-Time Product Managers (And What They Do All Day)," 2014. [Online]. Available:

https://www.smashingmagazine.com/author/rian-vander-merwe/. [Accessed: 15-Jun-2019].

[27] K. Bongard-Blanchy and C. Bouchard, "Dimensions of user experience-from the product design perspective," J. d'Interaction Pers., vol. 3, no. 1, 2014.

[28] R. W. Bly, The copywriter's handbook: a step-by-step guide to writing copy that sells. Holt Paperbacks, 2007.

[29] A. Wen, "The Go-to Guide for UX Writers, Copywriters, and Content Strategists," 2017. [Online]. Available: https://medium.com/talking-microcopywriting-ux/go-to-guide-for-ux-writers-copywriters-andcontent-strategists-3f216e0a0aa0. [Accessed: 15-Jun2019].

[30] K. Thoring, R. M. Müller, and others, "Understanding design thinking: A process model based on method engineering," in DS 69: Proceedings of E\&PDE 2011, the 13th International Conference on Engineering and Product Design Education, London, UK, 08.-09.09. 2011, 2011, pp. 493-498.

[31] E. Opara, Color works : best practices for graphic designers : an essential guide to understanding and applying color design principles. Beverly, MA: Rockport Publishers, 2014.

[32] A. Dillon, "User interface design," Encycl. Cogn. Sci., 2006.

[33] P. Madubuike, "The Role of a Designer in Early-Stage Startups. - UX Collective," 2017. [Online]. Available: https://uxdesign.cc/the-role-of-a-designer-in-earlystage-startups-5320cdf6f820. [Accessed: 15-Jun-2019].

[34] V. Joyce, "Animation principles for UX and UI designers," 2018. [Online]. Available: https://uxplanet.org/animation-that-matters-addingvalue-to-your-interface-65496fe $4 \mathrm{c} 182$. [Accessed: 15Jun-2019].

[35] B. Walker, "Maximize eCommerce Content To Drive Sales," Forrester Research, 2008. [Online]. Available: https://www.forrester.com/webinar/Maximize+eComm erce+Content+To+Drive+Sales/-/E-WEB2350\#. [Accessed: 16-Jun-2019].

[36] A. Schiller, "Digital Photography and the Ethics of Photo AlterationSenior Honors Thesis Digital Photography and the Ethics of Photo Alteration (2008)," Texas A\&M University, 2008.

[37] E. McLaughlin, The purpose is profit: the truth about starting and building your own business. Austin, Texas: Greenleaf, Book Group Press, 2016.

[38] W. Hockey, "Prioritizing Engineers In Your Startup Could Lead To Better Products," 2018. [Online]. Available:

https://www.forbes.com/sites/quora/2018/01/22/prioriti zing-engineers-in-your-startup-could-lead-to-betterproducts/\#28aa801a499f. [Accessed: 16-Jun-2019].

[39] E. Klotins, M. Unterkalmsteiner, and T. Gorschek, "Software engineering in start-up companies: An analysis of 88 experience reports," Empir. Softw. Eng., vol. 24, no. 1, pp. 68-102, 2019.

[40] G. Tavakoli, M. Feyz Arefi, O. Heidari, and M.
Mirjafari, "Designing conceptual model of after-sales services, in companies producing the capital goods, with the idea of value co-creation," Int. J. Qual. Serv. Sci., vol. 8, no. 2, pp. 122-142, Jun. 2016.

[41] C. P. McLaughlin and J. A. Fitzsimmons, "Strategies for globalizing service operations," Int. J. Serv. Ind. Manag., vol. 7, no. 4, pp. 43-57, 1996.

[42] G. Ambrose and P. Harris, The Fundamentals of Graphic Design. AVA Publishing SA, 2009.

[43] R. Rousi and J. Silvennoinen, "Simplicity and the art of something more: A cognitive-semiotic approach to simplicity and complexity in human-technology interaction and design experience," Hum. Technol., vol. 14, no. 1, 2018.

[44] A. Nikolov, "Design principle: Consistency - UX Collective," 2017. [Online]. Available: https://uxdesign.cc/design-principle-consistency6b0cf7e7339f. [Accessed: 16-Jun-2019].

[45] P. Do, "The impact of product photography on consumer attention and perception: A conjoint analysis study," 2018.

[46] T. L. Saaty, The Analytic Hierarchy Process: Planning, Priority Setting, Resource Allocation. McGraw-Hill, 1980.

[47] M. Bernasconi, C. Choirat, and R. Seri, "The analytic hierarchy process and the theory of measurement," Manage. Sci., vol. 56, no. 4, pp. 699-711, 2010.

[48] A. D. Sutadian, N. Muttil, A. G. Yilmaz, and B. J. C. Perera, "Using the Analytic Hierarchy Process to identify parameter weights for developing a water quality index," Ecol. Indic., vol. 75, pp. 220-233, 2017.

[49] T. L. Saaty, "How to make a decision: the analytic hierarchy process," Interfaces (Providence)., vol. 24, no. 6, pp. 19-43, 1994.

[50] E. Albayrak and Y. C. Erensal, "Using analytic hierarchy process (AHP) to improve human performance: An application of multiple criteria decision making problem," J. Intell. Manuf., vol. 15, no. 4, pp. 491-503, 2004.

[51] C. D. Koksal and N. M. Ozmutaf, "Using analytic hierarchy process for selecting the appropriate host country to study english language abroad," Int. J. Soc. Sci. Humanit. Stud., vol. 1, no. 1, pp. 37-46, 2009.

[52] H. Singer and \cSÜKRÜ ÖZlcSAH\.IN, "Employing an analytic hierarchy process to prioritize factors influencing surface roughness of wood and woodbased materials in the sawing process," Turkish J. Agric. For., vol. 42, no. 5, pp. 364-371, 2018.

[53] G. Abdollahzadeh, C. A. Damalas, M. S. Sharifzadeh, and H. Ahmadi-Gorgi, "Selecting strategies for rice stem borer management using the Analytic Hierarchy Process (AHP)," Crop Prot., vol. 84, pp. 27-36, 2016.

[54] S. Lee, W. Kim, Y. M. Kim, and K. J. Oh, "Using AHP to determine intangible priority factors for technology transfer adoption," Expert Syst. Appl., vol. 39, no. 7, pp. 6388-6395, 2012.

[55] F. Ahammed and A. Azeem, "Selection of the most appropriate package of Solar Home System using Analytic Hierarchy Process model in rural areas of Bangladesh," Renew. Energy, vol. 55, pp. 6-11, 2013. 